\title{
BH3-Only Proapoptotic Bcl-2 Family Members Noxa and Puma Mediate Neural Precursor Cell Death
}

\author{
Rizwan S. Akhtar, ${ }^{1,2}$ Ying Geng, ${ }^{1}$ Barbara J. Klocke, ${ }^{1}$ Cecelia B. Latham, ${ }^{1}$ Andreas Villunger, ${ }^{3}$ Ewa M. Michalak, ${ }^{4}$ \\ Andreas Strasser, ${ }^{4}$ Steven L. Carroll, ${ }^{1}$ and Kevin A. Roth ${ }^{1,2}$ \\ ${ }^{1}$ Division of Neuropathology, Department of Pathology and 2Department of Neurobiology, University of Alabama at Birmingham, Birmingham, Alabama \\ 35294, ${ }^{3}$ Division of Experimental Pathophysiology and Immunology, Biocenter, Innsbruck Medical University, A-6020 Innsbruck, Austria, and ${ }^{4}$ The Walter \\ and Eliza Hall Institute of Medical Research, Melbourne, Victoria 3050, Australia
}

Neural precursor cells (NPCs) are highly sensitive to genotoxic injury, which triggers activation of the intrinsic mitochondria-dependent apoptotic pathway. This pathway is typically initiated by members of the BH3 (Bcl-2 homology 3)-only subgroup of the Bcl-2 (B-cell CLL/lymphoma 2) protein family, which are positioned upstream in the apoptotic pathway to respond to specific death stimuli. We have shown previously that NPCs deficient in the tumor suppressor protein $\mathrm{p} 53$ show significantly less death after exposure to genotoxic injury or to staurosporine (STS), a broad kinase inhibitor and potent apoptosis inducer. $\mathrm{p} 53$ has been shown to regulate the expression of both Noxa and Puma, two BH3-only proteins, although their involvement in p53-dependent cell death appears to be cell-type and stimulus specific. A systematic comparison of the relative contributions of Noxa and Puma to NPC apoptosis has not yet been performed. We hypothesized that p53-dependent transcription of Noxa and Puma leads to death in telencephalic NPCs exposed to genotoxic stress. We found that genotoxic injury induces a rapid p53-dependent increase in expression of Noxa and Puma mRNA in telencephalic NPCs. Furthermore, deficiency of either Noxa or Puma inhibited DNA damage-induced caspase-3 activation and cell death in telencephalic NPCs in vitro. However, only Puma deficiency protected telencephalic ventricular zone NPCs from death in vivo. In contrast to genotoxic injury, STS produced a p53-independent increase in Noxa and Puma expression, but neither Noxa nor Puma was required for STSinduced NPC death. Together, these experiments identify Noxa and Puma as important regulators of genotoxin-induced telencephalic NPC death.

Key words: caspases; apoptosis; Bcl-2; p53; transcription; staurosporine

\section{Introduction}

Neural precursor cells (NPCs) include both multipotent neural stem cells and lineage-restricted neural progenitor cells (Rao, 1999). NPCs are found in the embryonic ventricular zone of the forebrain, in the external granule cell layer of the postnatal cerebellum, and in neurogenic regions of the adult brain (Temple, 2001). Unlike postmitotic neurons, NPCs are extremely sensitive to genotoxic injury (Roth and D'Sa, 2001; Akhtar and Roth, 2006).

Members of the Bcl-2 (B-cell CLL/lymphoma 2) family of proteins are activated by a variety of apoptotic stimuli, including genotoxic injury, in mammalian cells (Huang and Strasser, 2000; Cory et al., 2003). In NPCs, the proapoptotic Bcl-2 molecules Bax (Bcl-2-associated X protein) and Bak (Bcl-2-antagonist/killer)

Received Jan. 16, 2006; revised May 24, 2006; accepted May 28, 2006.

This work was supported by National Institutes of Health Grants NS35107, NS41962, and NS48353. R.S.A. is supported by University of Alabama at Birmingham Medical Scientist Training Program Grant GM008361. A.V. is supported by the Austrian Science Fund (Special Research Programs SFB021 and START). A.S. is supported by the National Health and Medical Research Council (Canberra, Australia), the Leukemia and Lymphoma Society of America, and the Virtual Research Institute of Ageing.

Correspondence should be addressed to Dr. Kevin A. Roth, Division of Neuropathology, Department of Pathology, University of Alabama at Birmingham, Sparks Center 961, 1530 3rd Avenue South, Birmingham, AL 35294-0017. E-mail:kroth@path.uab.edu.

DOI:10.1523/JNEUROSCI.0196-06.2006

Copyright $\odot 2006$ Society for Neuroscience $\quad$ 0270-6474/06/267257-08\$15.00/0 mediate the release of mitochondrial cytochrome $c$ into the cytosol after genotoxic stress (D'Sa et al., 2003; Lindsten et al., 2003). Furthermore, p53 is essential for DNA damage-induced death of NPCs (D'Sa-Eipper et al., 2001; Semont et al., 2004). A subgroup of the Bcl-2 family, the so-called BH3 (Bcl-2 homology 3)-only proteins, are activated (transcriptionally and/or posttranslationally) by a variety of intracellular and extracellular death stimuli (Akhtar et al., 2004) and relay signals to proapoptotic and antiapoptotic multi-BH domain Bcl-2 family members, such as Bax, Bak, Bcl-2, and Bcl- $\mathrm{X}_{\mathrm{L}}$. The $\mathrm{BH} 3$-only proteins that link DNA damage-induced p53 activation to Bax- and Bakdependent apoptosis of NPCs have been incompletely defined, but Noxa and Puma have been implicated on the basis of studies in other cell types (Villunger et al., 2003). Whether Noxa, Puma, or both are induced by p53 depends on the cell type and the nature of the apoptotic stimulus (Coultas et al., 2002). Puma appears to be critical for $\gamma$-irradiation-induced NPC apoptosis in postnatal cerebellar external granule cells (Jeffers et al., 2003). However, it is unclear whether other BH3-only molecules, such as Noxa, are involved in this process or whether Puma has a similar function in telencephalic NPCs.

In many but not all cases, the expression of Noxa and Puma in response to apoptotic stimuli is p53 dependent (Oda et al., 2000; Han et al., 2001; Nakano and Vousden, 2001; Yu et al., 2001; Fei 
et al., 2002; Schuler et al., 2003; Shibue et al., 2003; Cregan et al., 2004; Kim et al., 2004; Kiryu-Seo et al., 2005; Wong et al., 2005). However, induced expression of either Noxa or Puma in response to other apoptotic stimuli (e.g., glucocorticoids) has been observed in certain p53-deficient cells (e.g., thymocytes) (Han et al., 2001; Fei et al., 2002; Reimertz et al., 2003; Hershko and Ginsberg, 2004; Kim et al., 2004; Qin et al., 2004; Luo et al., 2005). In this report, we investigated the expression of Noxa and Puma in telencephalic NPCs exposed to genotoxic stress. We used staurosporine (STS), which induces p53-dependent yet transcriptionindependent apoptosis in NPCs, to ascertain whether Noxa or Puma expression in NPCs was stimulus specific (D'Sa-Eipper and Roth, 2000;Akhtar et al., 2006). To determine whether these proteins are regulated by a 553 -independent process, we measured Noxa and Puma expression in p53-deficient NPCs. Finally, we examined the requirement for these $\mathrm{BH} 3$-only proteins in DNA damage-induced death using NPCs that lack either Noxa or Puma. Our findings identify both Noxa and Puma as important mediators of p53-dependent apoptosis in telencephalic NPCs.

\section{Materials and Methods}

Chemicals. Cytosine arabinoside (AraC), camptothecin (CPT), bleomycin (BLM), etoposide (ETO), and STS were purchased from Sigma (St. Louis, MO). BOC-aspartyl(Ome)-fluoromethyl ketone (BAF) was purchased from MP Biomedicals (Aurora, OH).

Mice. The generation of mice with gene disruptions in Noxa and Puma has been described previously (Villunger et al., 2003). These mice were generated on an inbred C57BL/6 background using C57BL/6-derived embryonic stem cells. $p 53^{+/-}$mice were purchased from Taconic Farms (Germantown, NY). The p53 mutant mice were originally generated on a mixed C57BL/6 $\times 129$ SV background using 129SV-derived embryonic stem cells but had been backcrossed onto the C57BL/ 6 background for five generations before use in our studies. Endogenous and disrupted genes were detected by PCR analysis of DNA extracts from limb or tail samples as described previously (D'Sa-Eipper et al., 2001; Villunger et al., 2003). The morning on which a vaginal plug was seen was designated as embryonic day 0.5 (E0.5). Mice were cared for in accordance with the guidelines of the National Institues of Health Guide for the Care and Use of Laboratory

Animals. All animal protocols were approved by the Institutional Animal Care and Use Committee of the University of Alabama at Birmingham.

FGF2-expanded NPC cultures. FGF2 has been shown previously to maintain NPCs in an undifferentiated state while serving as a mitotic stimulus for their proliferation (Vescovi and Snyder, 1999). As described previously (D'Sa-Eipper et al., 2001), telencephalic NPC cultures were prepared from embryos harvested between gestational days 12 and 13 . Briefly, telencephalic vesicles were isolated, and cells were dissociated for $20 \mathrm{~min}$ at $37^{\circ} \mathrm{C}$ in HBSS (Invitrogen, Carlsbad, CA) containing $0.05 \%$ trypsin with $0.02 \%$ EDTA, $0.001 \%$ DNase I, and $0.2 \%$ bovine serum albumin (BSA) (all from Sigma). Trypsinization was stopped by adding an equal volume of $10 \%$ fetal calf serum (FCS) in either HBSS or DMEM (Invitrogen). Tissue digests were dissociated using several rounds of trituration using a fire-polished Pasteur pipette. Cells were washed once with HBSS containing $0.2 \%$ BSA and then resuspended in DMEM containing $20 \mathrm{ng} / \mathrm{ml} \mathrm{FGF2} \mathrm{(Research} \mathrm{Diagnostics,} \mathrm{Flanders,} \mathrm{NJ),} 8 \mu \mathrm{g} / \mathrm{ml}$ heparin, $5 \mu \mathrm{g} / \mathrm{ml}$ insulin, $100 \mu \mathrm{g} / \mathrm{ml}$ apotransferrin, $30 \mathrm{~nm}$ sodium selenite, $20 \mathrm{~nm}$ progesterone, $100 \mu \mathrm{m}$ putrescine, $6 \mathrm{~g} /$ liter glucose, $2 \mathrm{~mm}$ glutamine, $94.38 \mu \mathrm{M}$ 2-mercaptoethanol, $100 \mathrm{U} / \mathrm{ml}$ penicillin, and 100 $\mu \mathrm{g} / \mathrm{ml}$ streptomycin (all from Sigma), $\mathrm{pH}$ 7.4. Cells were incubated at $37^{\circ} \mathrm{C}$ in humidified $5 \% \mathrm{CO}_{2} / 95 \%$ air atmosphere. Fresh medium was added to cultures every $4 \mathrm{~d}$. Neurospheres were then removed and placed in HBSS containing $0.05 \%$ trypsin with $0.02 \%$ EDTA and $0.2 \%$ BSA at $37^{\circ} \mathrm{C}$ for $2 \mathrm{~min}$. Trypsinization was stopped by adding 2 vol of DMEM containing $10 \%$ FCS. Cells were washed with HBSS containing $0.2 \%$ BSA and then plated onto poly-L-lysine (Sigma)/laminin (BD Biosciences, Bedford, MA) coated tissue culture plates (Corning, Corning, NY). NPCs

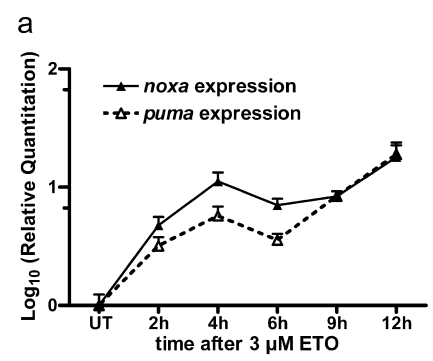

b
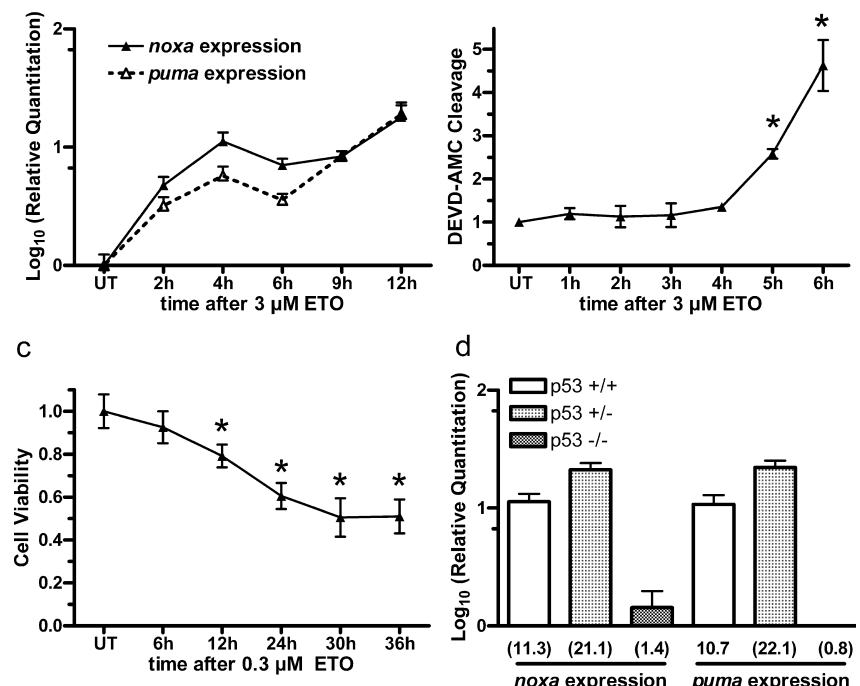

d

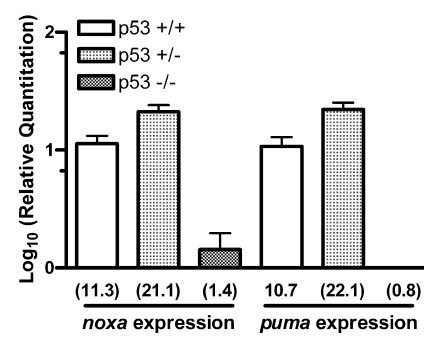

Figure 1. Genotoxic stimuli induce Noxa and Puma mRNA expression in NPCs through a p53-dependent mechanism. $\boldsymbol{a}$, An increase in Noxa mRNA expression was detected within $2 \mathrm{~h}$ of exposure to $3 \mu \mathrm{m}$ ETO. Similarly, an increase in Puma mRNA expression was detected within $2 \mathrm{~h}$ of exposure to $3 \mu \mathrm{m}$ ETO. $\boldsymbol{b}$, DEVD-AMC cleavage did not significantly increase until $5-6 \mathrm{~h}$ after exposure to $3 \mu \mathrm{mETO}$.c, Cell viability decreased significantly only after 12-36 h exposure to 0.3 $\mu \mathrm{M}$ ETO.d, After $6 \mathrm{~h}$ of exposure to $3 \mu \mathrm{m} \mathrm{AraC}$, Noxa and Puma expression increased in wild-type and p53-heterozygous NPCs but not in p53-deficient NPCs. Experiments in $\boldsymbol{a}$ and $\boldsymbol{d}$ were performed in the presence of $150 \mu \mathrm{m}$ BAF, a broad-spectrum caspase inhibitor, to inhibit apoptosis and thereby maximize recovery of mRNA. Levels of mRNA expression are shown relative to untreated controls (UT) and are indicated in parentheses below each column. Transcripts for either Noxa or Puma are normalized to 185 expression within each sample. No Noxa or Puma transcripts were detectable by real time RT-PCR in Noxa-deficient or Puma-deficient NPCs, respectively (data not shown). Data points in $\boldsymbol{b}$ and c represent mean $\pm \mathrm{SEM}$, with $n=8$. ${ }^{*} p<$ 0.001 by one-way ANOVA/Bonferroni's post hoc test versus untreated controls.

formed adherent monolayer cultures and were allowed to continue to grow for 2-4 d. Cells suspensions were prepared by trypsinization as described above and plated onto poly-L-lysine/laminin-coated 48-well tissue culture plates (Corning). A small aliquot of cells was stained with trypan blue and counted, and 30,000 cells were plated per well. Cultures were then incubated for another 2-4 d before being used in experiments.

Cell viability and in vitro caspase cleavage assays. As described previously (D'Sa et al., 2003), cells used for viability assays were washed once with Locke's buffer (in mM: $154 \mathrm{NaCl}, 5.6 \mathrm{KCl}, 3.6 \mathrm{NaHCO}_{3}, 2.3 \mathrm{CaCl}_{2}$, $1.2 \mathrm{MgCl}_{2}, 5.6$ glucose, and 5 HEPES, pH 7.4). Cells were incubated at $37^{\circ} \mathrm{C}$ for $30 \mathrm{~min}$ in Locke's buffer containing $5 \mu \mathrm{M}$ calcein-AM (Invitrogen). Calcein-AM conversion was read using a fluorescence plate reader (excitation, $488 \mathrm{~nm}$; emission, $530 \mathrm{~nm}$ ). Caspase activation was detected using an in vitro cleavage assays using 7-amino-4-methylcoumarin (AMC)-labeled caspase substrates (Bounhar et al., 2002). Cells used for in vitro caspase cleavage assays were lysed in $100 \mu \mathrm{l}$ of buffer A [10 mM HEPES, pH 7.4, $42 \mathrm{~mm} \mathrm{KCl}, 5 \mathrm{~mm} \mathrm{MgCl}_{2}, 1 \mathrm{~mm} \mathrm{DTT,} \mathrm{0.5 \%} \mathrm{3-[(3-}$ cholamidopropyl)dimethylammonio]-1-propanesulfonate (CHAPS), $10 \%$ sucrose, $1 \mathrm{~mm}$ PMSF, and $1 \mu \mathrm{g} / \mathrm{ml}$ leupeptin]. Then, $150 \mu \mathrm{l}$ of buffer B (25 mм HEPES, pH 7.4, 1 mm EDTA, 0.1\% CHAPS, 10\% sucrose, and $3 \mathrm{~mm}$ DTT) containing $10 \mu \mathrm{M}$ DEVD (acetyl-aspartyl-glutamyl-valyl)AMC (Biomol, Plymouth Meeting, PA) were added to cells, and the plate was incubated at $37^{\circ} \mathrm{C}$ for $30 \mathrm{~min}$. Generation of the fluorescent AMC caspase-3 cleavage product was measured using a fluorescence plate reader (excitation, $360 \mathrm{~nm}$; emission, $460 \mathrm{~nm}$ ). Both calcein-AM conversion and DEVD-AMC cleavage were expressed relative to untreated controls.

Quantitative real-time reverse transcription-PCR. After treatment, NPC suspensions were prepared by trypsinization as described above. Suspensions were centrifuged, and total RNA from the pellets was isolated using Trizol reagent (Invitrogen) according to the instructions of the manufacturer. One microgram of total RNA was incubated with 200 

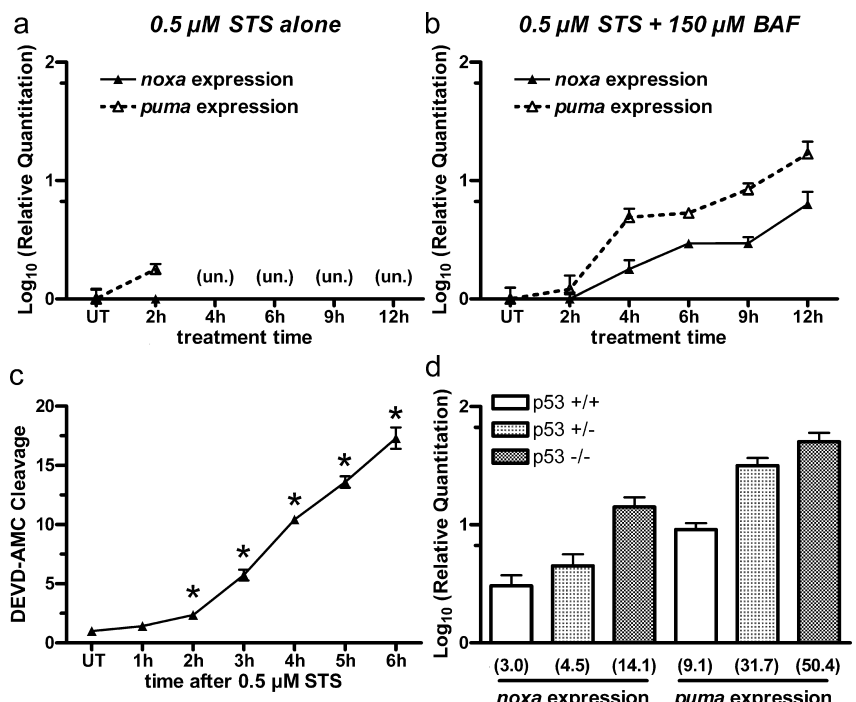

Figure 2. STS induces Noxa and Puma expression in NPCs independently of p53. $\boldsymbol{a}$, Exposure to $0.5 \mu \mathrm{m}$ STS did not significantly increase Noxa or Puma mRNA expression at $2 \mathrm{~h}$. By $4 \mathrm{~h}$, exposure to $0.5 \mu \mathrm{m}$ STS produced alterations in 185 expression, and Noxa and Puma mRNA induction was un-interpretable (un.). $\boldsymbol{b}$, In the presence of $150 \mu \mathrm{m}$ BAF, modest Noxa and Puma mRNA expression was seen by $4-6 \mathrm{~h}$ of exposure to $0.5 \mu \mathrm{m}$ STS. C, DEVD-AMC cleavage significantly increased within $2-3 \mathrm{~h}$ after exposure to $0.5 \mu \mathrm{m}$ STS. $d$, After treatment with $0.5 \mu \mathrm{m}$ STS for $6 \mathrm{~h}$, Noxa and Puma mRNA expression was induced in wild-type, p53-heterozygous, and p53-deficient NPCs. Experiments in $\boldsymbol{b}$ - $\boldsymbol{d}$ were done in the presence of $150 \mu \mathrm{M}$ BAF. UT, Untreated controls.

ng of random hexamers, $0.5 \mathrm{~mm}$ dNTPs, and RNase-free water at $65^{\circ} \mathrm{C}$ for $10 \mathrm{~min}$ (all from Invitrogen). Then, $5 \times$ first-strand buffer, $5 \mathrm{~mm}$ DTT, 40 U of RNaseOUT, and 200 U of SuperScript III reverse transcriptase were added, and the reaction mixture was incubated at room temperature for $5 \mathrm{~min}$, at $50^{\circ} \mathrm{C}$ for $60 \mathrm{~min}$, at $70^{\circ} \mathrm{C}$ for $15 \mathrm{~min}$, and at $4^{\circ} \mathrm{C}$ for $10 \mathrm{~min}$ (all reagents from Invitrogen). Absence of genomic DNA contamination was confirmed by performing PCR for actin or cyclophilin in parallel reactions performed identically except for the addition of reverse transcriptase (data not shown). Quantitative reverse transcription (RT)PCR was performed using TaqMan Gene Expression Assays and the Applied Biosystems (Foster City, CA) 7500 Real-Time PCR System according to the instructions of the manufacturer. Expression of Noxa was normalized to $18 S$, and data are expressed relative to untreated NPCs.

In vivo AraC treatment. Pregnant mice at gestational day 12.5 were intraperitoneally injected with $25 \mathrm{mg} / \mathrm{kg}$ AraC dissolved in $0.9 \%$ saline. Embryos were isolated $6 \mathrm{~h}$ later and placed in $4^{\circ} \mathrm{C}$ Bouin's fixative overnight, followed by paraffin embedding. Control embryos were similarly isolated, fixed, and embedded from untreated pregnant mice at gestational day 12.5. Seven micrometers sections were prepared and stained with hematoxylin and eosin. Stained sections were imaged using a Zeiss (Oberkochen, Germany) Axioskop equipped with an Axiocam MRc camera. Apoptotic nuclei were counted in four images per animal, and ventricular zone area was calculated using Axiovision software.

Immunohistochemistry. Paraffin-embedded tissue sections were deparaffinized, and endogenous peroxidase activity was blocked with $3 \%$ hydrogen peroxide in PBS. Sections were then incubated in PBSblocking buffer (PBS-BB) (PBS with $0.1 \%$ BSA, $0.3 \%$ Triton X-100, and $0.2 \%$ nonfat powdered dry milk) for $30 \mathrm{~min}$ at room temperature. Primary antibody was diluted in PBS-BB and applied to sections overnight at $4^{\circ} \mathrm{C}$. Primary antibodies and dilutions used were anti-p53 (1:1000; Ncl-p53-Cm5P rabbit polyclonal antiserum; Novocastra Laboratories, Newcastle upon Tyne, UK) and anti-activated caspase-3 (1:1000; catalog \#9661 rabbit polyclonal antiserum; Cell Signaling Technology, Beverly MA). After washes with PBS, sections were incubated with a donkey anti-rabbit horseradish peroxidase-conjugated secondary antibody (Jackson ImmunoResearch, West Grove, PA), diluted in PBS-BB (1:1500) for $1 \mathrm{~h}$ at room temperature. After washes with PBS, immuno- staining was detected using a tyramide signal amplification system (PerkinElmer, Boston, MA) according to the instructions of the manufacturer. Sections were counterstained with bisbenzimide $(2 \mu \mathrm{g} / \mathrm{ml}$; Hoechst 33,258; Sigma) and examined and imaged with a Zeiss AxioSkop microscope equipped with epifluorescence and an Axiocam MRc camera. Bisbenzimide-labeled nuclei that were condensed, round, and lacking visible nucleoli were counted in four images per animal. Ventricular zone area was calculated as above.

Statistical analysis. All data points represent mean \pm SEM. $n=8$ for all experiments unless stated otherwise. Statistical significance was established by one-way or two-way ANOVA, followed by Bonferroni's test for all pairwise comparisons.

\section{Results}

\section{Genotoxic stimuli induce transcriptional upregulation of Noxa and Puma in NPCs}

To initially examine the roles that Noxa and Puma play in the regulation of NPC death, we isolated telencephalic NPCs from E12-E13 wild-type mice. After in vitro expansion with FGF2, we exposed NPCs to different apoptotic stimuli, including the following: AraC, a nucleoside analog; BLM, an inducer of singleand double-stranded DNA breaks; CPT, an inhibitor of DNA-topoisomerase complexes; and ETO, an inhibitor of DNA topoisomerase, which induces single- and double-stranded DNA breaks (Burger, 1998; Grant, 1998; Hande, 1998; Liu et al., 2000). The effects of these agents on Noxa and Puma mRNA expression were then examined by real-time quantitative RT-PCR. We found that exposure to $\mathrm{AraC}(1 \mu \mathrm{M})$ for $24 \mathrm{~h}$ induced an approximately threefold increase in Puma mRNA expression. Furthermore, exposure to BLM $(3 \mu \mathrm{M})$, CPT $(1 \mu \mathrm{M})$, or ETO $(1 \mu \mathrm{M})$ for $24 \mathrm{~h}$ induced a fivefold increase in Puma mRNA expression. We demonstrated previously that these stimuli also induce Noxa mRNA expression in NPCs (Akhtar et al., 2006). Thus, both Noxa and Puma are viable candidates for mediating p53 transcriptiondependent apoptosis of telencephalic NPCs.

$\mathrm{BH} 3$-only proteins are thought to transduce apoptotic signals in response to diverse death stimuli and to ultimately modulate the activity of multidomain Bcl-2 family members (Huang and Strasser, 2000; Cory et al., 2003). Accordingly, activation of BH3only proteins often occurs early in apoptosis. We therefore hypothesized that transcriptional activation of Noxa and Puma must occur before the onset of significant caspase activation and apoptotic death. We observed that Noxa mRNA expression increased by approximately fivefold and Puma by threefold within $2 \mathrm{~h}$ of exposure to ETO (Fig. 1a). Expression of both Noxa and Puma mRNA was increased by 5- to 10 -fold at 4-6 h (Fig. 1a). Caspase-3 is the primary effector caspase in NPCs, and we assessed its activation by measuring the enzymatic cleavage of DEVD-AMC, a substrate for all executioner caspases (caspase-3, caspase-6, and caspase-7) (Bounhar et al., 2002). We found that significant DEVD-AMC cleavage did not occur until $\sim 6 \mathrm{~h}$ after ETO exposure (Fig. 1b). To measure cell viability, we used a calcein conversion assay and found that significant cell death occurred only after $12 \mathrm{~h}$ of exposure to ETO $(0.3 \mu \mathrm{M})$ (Fig. $1 c)$, well after the onset of Noxa and Puma mRNA induction (Fig. 1a). Together, these results indicate that genotoxic injury induces increased expression of both Noxa and Puma mRNA in NPCs and that this increased expression precedes caspase- 3 activation and cell death.

\section{p53 regulation of Noxa and Puma expression in NPCs is stimulus specific}

We hypothesized that if Noxa or Puma mRNA expression was required for DNA damage-mediated NPC death, p53-deficient 
NPCs would show diminished Noxa and/or Puma induction after treatment with cytotoxic drugs. We therefore generated FGF2-expanded NPCs from wildtype, p53-heterozygous, and p53-deficient embryos and exposed these cells to AraC. Both wild-type and p53-heterozygous NPCs displayed greater than 10-fold induction of Noxa and Puma mRNA after

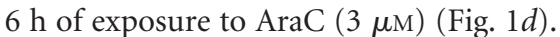
In contrast, p53-deficient NPCs showed no increase in the expression of either Noxa or Puma mRNA after AraC exposure (Fig. 1d). These results demonstrate that upregulation of the expression of both Noxa and Puma mRNA after DNA damage requires $\mathrm{p} 53$.

We have shown previously that STSinduced NPC death is p53 dependent but does not require new macromolecular synthesis (Akhtar et al., 2006). To extend these findings, we examined the expression of Noxa and Puma mRNA in NPCs after exposure to STS. NPCs exposed to STS for $2 \mathrm{~h}$ did not show an increase in the expression of Noxa or Puma mRNA (0.5 $\mu \mathrm{M}$ ) (Fig. 2a,b), in contrast to the effect seen after genotoxic injury (Fig. 1a). By $4 \mathrm{~h}$ of exposure to STS, we were unable to assess the expression of Noxa or Puma by real time RT-PCR because of significant alterations in $18 S \mathrm{mRNA}$, which was used as an endogenous control (Fig. $2 a$ ). Because STS induces rapid apoptosis in NPCs within $6 \mathrm{~h}$ of exposure (see below), we hypothesized that inhibiting caspase activation would prevent rapid apoptotic death and maximize the detection of Noxa and Puma mRNA. Thus, we repeated these studies using NPCs treated with BAF, a broad-spectrum caspase inhibitor. In the presence of $150 \mu \mathrm{M}$ BAF, Noxa mRNA expression increased by twofold to threefold and Puma by approximately fivefold after 4-6 h of STS exposure (Fig. $2 b$ ). STS led to significant DEVDAMC cleavage by $2-3 \mathrm{~h}$ after exposure (Fig. $2 c$ ). Together, these results indicate that STS does not induce as rapid or robust an increase in Noxa or Puma mRNA expression as does genotoxic injury. Furthermore, expression of Noxa and Puma mRNA in STS-treated NPCs does not precede caspase-3 activation.

Although expression of Noxa and Puma is thought to be primarily regulated by $\mathrm{p} 53$, several reports have suggested that transcription of these genes may also be regulated by a p53independent process (Reimertz et al., 2003; Hershko and Ginsberg, 2004; Wong et al., 2005). We hypothesized that Noxa or Puma expression in STS-treated NPCs (Fig. $2 b$ ) may be p53 independent. After $6 \mathrm{~h}$ of STS treatment, induction of Noxa mRNA levels were increased by approximately threefold in wildtype NPCs and by approximately fourfold in p53-heterozygous NPCs $(0.5 \mu \mathrm{M})$ (Fig. 2d). In p53-deficient NPCs, Noxa mRNA expression was increased by approximately 14 -fold (Fig. $2 d$ ). This result indicated that p53 is not essential for STS-induced Noxa mRNA induction. Similarly, STS treatment caused an approximately ninefold induction of Puma mRNA expression in wild- type NPCs and more than 25-fold induction of Puma mRNA in p53-heterozygous and p53-deficient NPCs (Fig. 2d). Together, these findings demonstrate that STS induces p53-independent transcription of Noxa and Puma, whereas transcription of Noxa and Puma after DNA damage is solely mediated by p53. Furthermore, these results suggest that, in the absence of p53, staurosporine-induced Noxa and Puma expression may increase and/or become more readily detectable.

\section{Both Noxa and Puma are essential for DNA damage-induced NPC death in vitro}

Our results indicate that either Noxa or Puma or both may function as the essential link between activation of p53 and the subsequent engagement of the intrinsic apoptotic signaling pathway. To directly test this hypothesis, we prepared FGF2-expanded telencephalic NPCs from wild-type, Noxa-deficient, or Pumadeficient embryos and assessed their response to DNA damage. After exposure to $0.03-3.0 \mu \mathrm{M}$ AraC, we found that AraCinduced death was significantly reduced in Noxa-deficient NPCs (Fig. $3 a$ ). Death in response to $0.1-1.0 \mu \mathrm{M}$ ETO exposure was also reduced in Noxa-deficient NPCs (Fig. 3e). Consistent with these observations, we found that DEVD-AMC cleavage was markedly 
reduced in Noxa-deficient NPCs exposed to AraC compared with wild-type or Noxa-heterozygous $\left(\mathrm{Noxa}^{+/-}\right.$) NPCs (Fig. 3b). DEVD-AMC cleavage induced by $0.1-1.0 \mu \mathrm{M}$ ETO was also reduced in Noxa-deficient NPCs (Fig. 3f). These findings indicate that Noxa regulates DNA damage-induced caspase- 3 activation and cell death in FGF2-expanded NPCs in vitro. To examine the requirement for Puma in DNA damage-induced killing of NPCs, we exposed wild-type, Puma-heterozygous, and Puma-deficient NPCs to $0.03-3.0 \mu \mathrm{M}$ AraC. These experiments showed that AraC-induced death was significantly reduced in Puma-deficient NPCs compared with wild-type NPCs (Fig. 3c). Furthermore, a significant protective effect of Puma heterozygosity Puma $^{+/-}$ cells) was seen after DNA damage (Fig. $3 c$ ), which was not seen in Noxa-heterozygous NPCs (Fig. 3a). Death in response to 0.1-10 $\mu \mathrm{M}$ BLM exposure was also reduced in Puma-deficient NPCs (Fig. $3 g$ ). We also found that caspase-3 activation was markedly reduced in Puma-deficient NPCs exposed to 0.03-3.0 $\mu \mathrm{M} \mathrm{AraC}$ compared with similarly treated wild-type NPCs (Fig. $3 d$ ). Collectively, these findings demonstrate that, over the timeframe investigated, Noxa and Puma appear to participate in and are necessary for independent death signaling pathways after DNA damage in NPCs.

\section{STS-induced NPC death is independent of Noxa and Puma}

We demonstrated previously that STS-induced death is regulated by p53 but does not require new macromolecular synthesis or induction of p53-dependent gene transcription (Akhtar et al., 2006). Therefore, we hypothesized that Noxa and Puma may be dispensable for STS-induced NPC death. We tested this idea by preparing FGF2-expanded NPCs from wild-type, Noxadeficient, or Puma-deficient NPCs and exposed them to STS. STS induced an equivalent, concentration-dependent cell death in wild-type, Noxa-heterozygous, and Noxa-deficient NPCs after $6 \mathrm{~h}$ of exposure (Fig. $4 a$ ), indicating that STS-induced NPC death is indeed independent of Noxa. We performed similar experiments to test the requirement for Puma in STS-induced NPC death. After 0.01-1.0 $\mu \mathrm{M}$ STS exposure for $6 \mathrm{~h}$, loss of Puma did not provide a protective effect during STS-induced NPC death compared with wild-type or Puma-heterozygous cells (Fig. 4b). Thus, Noxa and Puma regulate NPC death in a stimulus-specific manner.

\section{Puma but not Noxa is essential for DNA damage-induced telencephalic NPC death in vivo}

Our experiments with in vitro FGF2-expanded NPCs indicate that both Noxa and Puma mediate NPC apoptosis after DNA damage. To investigate the relevance of these findings to genotoxic injury-induced telencephalic NPC apoptosis in vivo, Noxaor Puma-heterozygous adult mice were interbred, and, on approximately gestational day $12-13$, dams were intraperitoneally injected with $25 \mathrm{mg} / \mathrm{kg}$ AraC. Embryos were isolated $6 \mathrm{~h}$ later, and cells with apoptotic nuclei were counted in telencephalic ventricular zones from multiple animals of each genotype. To assess baseline cell death in the normal neocortex, control embryos were similarly isolated from untreated Noxa- or Pumaheterozygous dams. Ventricular zone from untreated wild-type, Puma-heterozygous, or Puma-deficient mice had extremely low numbers of apoptotic cells (Fig. $5 a-c$ ). Similarly, untreated wildtype, Noxa-heterozygous, and Noxa-deficient mice had scant apoptotic cells (Fig. $5 g-i$ ), indicating that levels of normal baseline apoptosis in the ventricular zone is low and not altered by Noxa or Puma deficiency. In contrast, AraC-treated embryos that were wild type or heterozygous for Noxa or Puma contained numer-
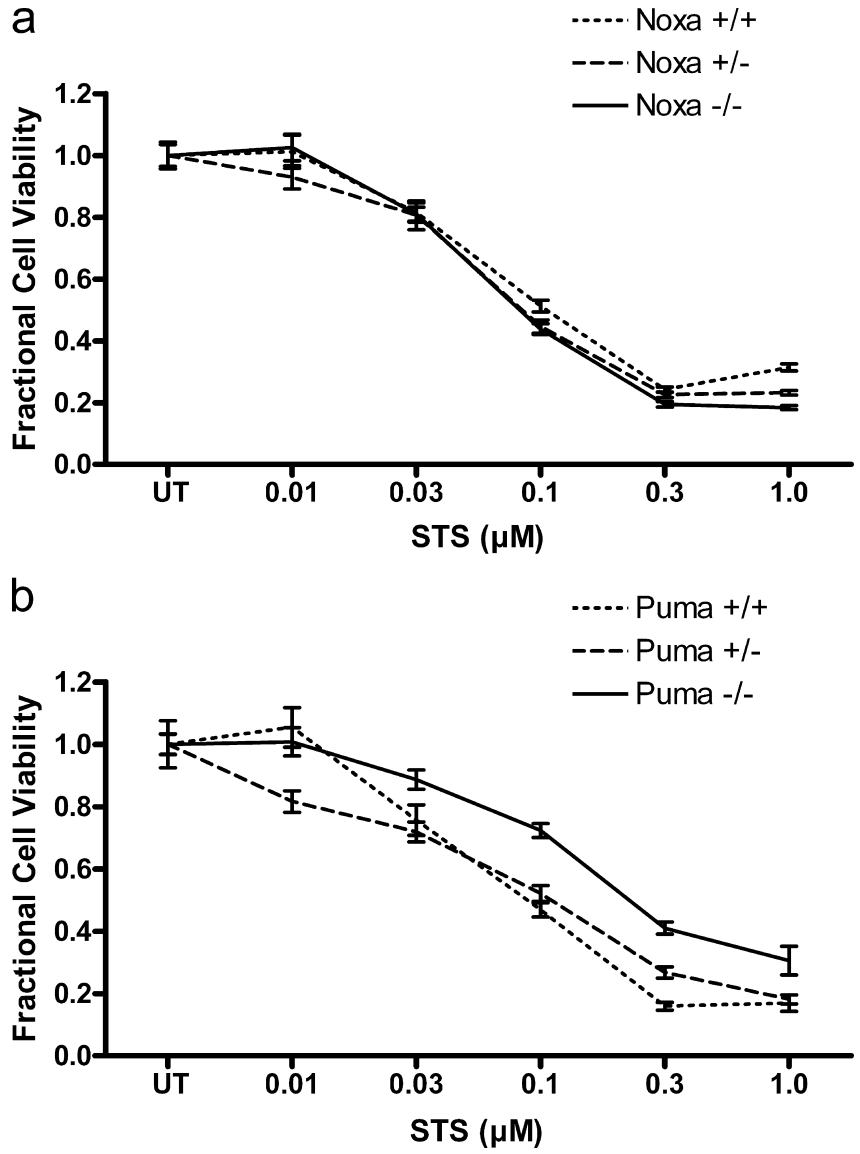

Figure 4. Noxa and Puma are not essential for STS-induced NPC death. $\boldsymbol{a}$, Exposure to STS for $6 \mathrm{~h}$ induced significant cell death in wild-type NPCs, and this death was not affected by loss of Noxa. $\boldsymbol{b}$, Similarly, loss of Puma did not significantly affect death after $6 \mathrm{~h}$ of exposure to STS. Cell viability was normalized to untreated controls (UT).

ous apoptotic cells throughout the ventricular zone (Fig. $5 d$,e$, j, k, m, n)$. In contrast, AraC-induced NPC apoptosis was significantly reduced in Puma-deficient embryos (Fig. $5 f, m$ ), indicating that Puma is essential for DNA damage-induced NPC apoptosis in vivo. Surprisingly, AraC-exposed Noxa-deficient embryos displayed many apoptotic cells (Fig. $5 l, n$ ), similar in number to that seen in wild-type or heterozygous $\left(\mathrm{Noxa}^{+/-}\right)$embryos. Thus, although Noxa deficiency significantly reduced DNA damageinduced NPC death in vitro (Fig. $3 a$ ), Noxa was not critical for telencephalic NPC death in vivo (Fig. $5 f, h$ ).

Because Puma deficiency significantly protected NPCs from DNA damage-induced apoptosis in vivo and in vitro, we hypothesized that Puma may be situated between p53 stabilization and caspase- 3 activation in an obligate signaling pathway. To test this hypothesis, we assessed immunoreactivity of p53 and activated caspase- 3 in the ventricular zone of untreated or AraC-treated embryos. As expected, untreated embryos showed only weak p53 immunoreactivity in the telencephalic ventricular zone of wildtype, Puma-deficient, or Noxa-deficient embryos (Fig. $6 a-d$ ). Furthermore, only rare activated caspase-3-immunoreactive cells were seen in untreated embryos (Fig. 6i-l). In AraC-treated wildtype embryos, activated caspase-3 immunoreactivity was markedly increased in the ventricular zone (Fig. $6 \mathrm{~m}, \mathrm{o}$ ). Compared with AraC-treated wild-type embryos, immunoreactivity for activated caspase-3 was substantially reduced in AraC-treated Pumadeficient embryos (Fig. 6n) and was associated with a dramatic increase in p53 immunoreactivity (Fig. 6f). In contrast, increased 
p53 immunoreactivity after AraC treatment is not seen in Noxa-deficient embryos (Fig. 6h), and activation of capase-3 is prominent in both wild-type and Noxadeficient telencephalon (Fig. 6p). Thus, the dramatic alterations in p53 and activated caspase- 3 immunoreactivity seen in AraC-treated Puma-deficient embryos were not seen in Noxa-deficient embryos. Together, these findings show that Puma is situated between p53 stabilization and caspase- 3 activation in a linear signaling pathway after DNA damage.

\section{Discussion}

$\mathrm{BH} 3$-only proteins are thought to act as integrators of various stress signals and initiators of apoptosis (Huang and Strasser, 2000; Cory et al., 2003; Akhtar et al., 2004). In this report, we investigated whether the proapoptotic BH3-only proteins Noxa and/or Puma are critical for DNA damage-induced apoptosis of NPCs. We hypothesized that Noxa and Puma, as p53-target genes, may be transcriptionally activated after genotoxic injury. Using FGF2-expanded telencephalic NPCs, we showed that both Noxa and Puma mRNA levels are induced in response to genotoxic injury in a p53-dependent manner. Furthermore, by testing NPCs with disruptions in either Noxa or Puma, we showed that both $\mathrm{BH} 3$-only proteins are involved in the apoptotic response of NPCs to genotoxic injury. We confirmed that Puma regulates telencephalic NPC death in vivo by testing embryos containing two mutant alleles of Puma. However, we found that Noxa deficiency did not protect telencephalic ventricular zone NPCs from genotoxic injury-induced apoptosis in vivo. Consistent with our histopathological analysis, AraC-treated Pumadeficient embryos exhibited markedly decreased caspase-3 activation compared with AraC-treated wild-type and Pumaheterozygous littermates. In Puma-deficient embryos, AraC treatment also led to a dramatic increase in detectable p53 immunoreactivity. This finding indicates that interruption of DNA damage-induced apoptotic signaling through Puma results in telencephalic NPCs that have accumulated p53 but cannot activate caspase-3. Collectively, our studies indicate that Puma links p53 and activation of the intrinsic apoptotic pathway in NPCs in vivo and identify both Noxa and Puma as potentially key p53dependent activators of the intrinsic apoptotic pathway in NPCs. Our findings are consistent with a previous report demonstrating that loss of Puma dramatically decreased apoptotic death after $\gamma$-irradiation in the external granule cell layer of the cerebellum, the dentate gyrus of the hippocampus, and the telencephalic subventricular zone in postnatal mice (Jeffers et al., 2003).

In this paper, we show that deficiency of either Noxa or Puma protects FGF2-expanded NPCs from genotoxic injury-induced caspase- 3 activation and cell death. However, in vivo, only Puma deficiency attenuated AraC-induced embryonic telencephalic NPC death. Interestingly, a small subpopulation of telencephalic NPCs still underwent apoptosis in Puma-deficient embryonic brains (Fig. $5 f$ ). This small subpopulation of ventricular zone
NPCs may primarily depends on Noxa expression for genotoxininduced death, although given their rarity, the survival of these cells in Noxa-deficient brain cannot be easily discerned (Fig. $5 l$ ). Because stimulation with different growth factors has been demonstrated to expand different subpopulations of telencephalic NPCs (Maric et al., 2003; Maric and Barker, 2004), we hypothesize that FGF2 produces selective expansion of a subpopulation of NPCs that has different requirements for apoptosis than the majority of ventricular zone NPCs in vivo. Alternatively, in vitro culture conditions may alter expression of proapoptotic or antiapoptotic factors that cooperate with Noxa to regulate DNA damage-induced apoptosis. A comprehensive analysis of proapoptotic and antiapoptotic genes induced in NPCs in vitro versus in vivo may provide insight into these processes.

Our results demonstrate that Noxa and Puma are not interchangeable proapoptotic mediators during DNA damageinduced NPC death. Rather, deficiency of either Noxa or Puma in NPCs provides protection against this stimulus in vitro. We speculate that this "dual requirement" indicates that Noxa and Puma have nonequivalent proapoptotic functions. A recent study demonstrated that Puma can potently bind and inhibit all antiapoptotic Bcl-2 family members, whereas Noxa acts only on Mcl-1 (myeloid cell leukemia 1) and Bcl2A1 (Bcl2-related protein A1) but not on Bcl-2 or Bcl- $\mathrm{X}_{\mathrm{L}}$ (Chen et al., 2005). This finding may explain the fact that Puma deficiency provides greater protection than Noxa deficiency does against DNA damage-induced NPC death in vivo. It remains to be determined whether dual deficiency of Noxa and Puma, like dual deficiency of Bax and Bak, 


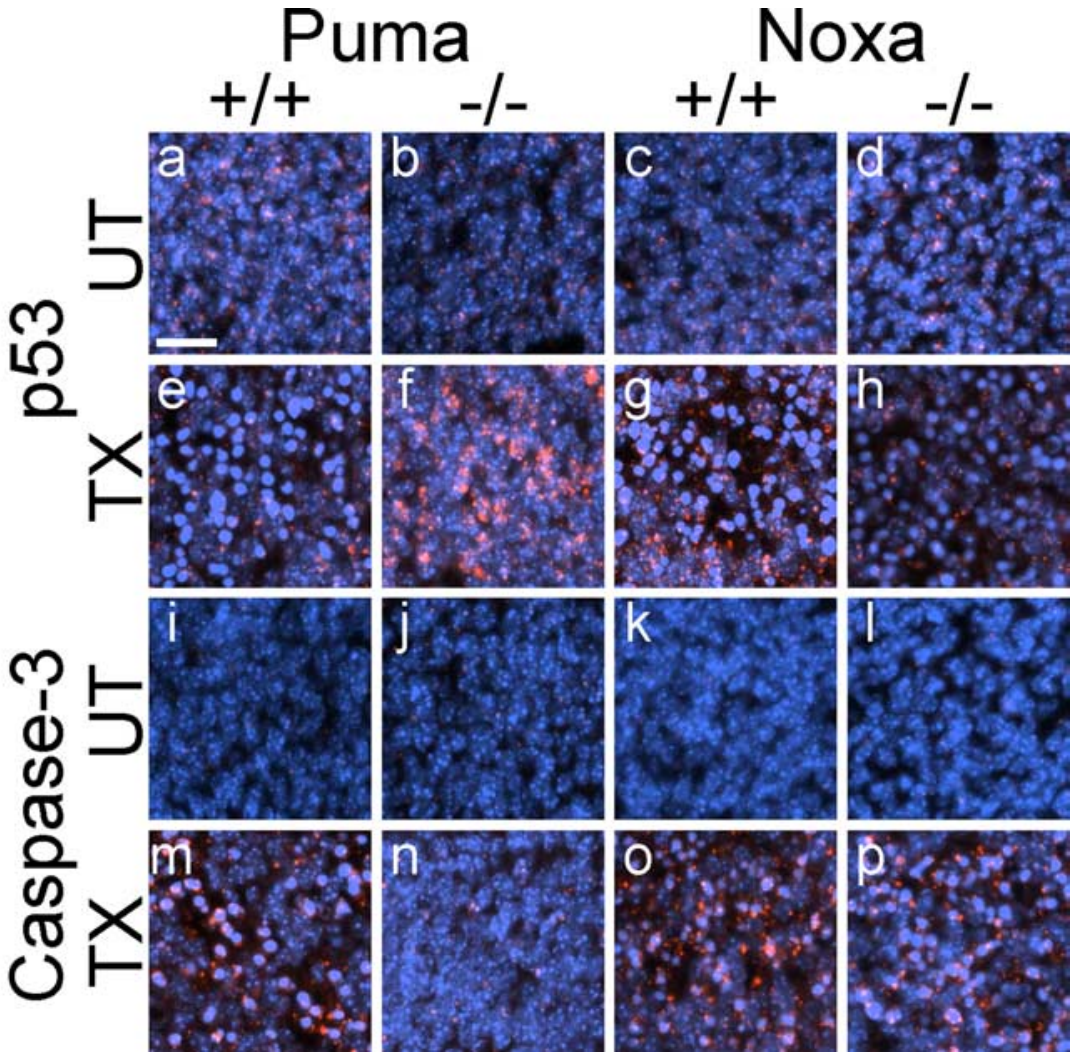

Figure 6. L Loss of Puma affects p53 immunoreactivity and caspase-3 activation in telencephalic NPCs after genotoxic injury. $\boldsymbol{a}-\boldsymbol{d}$, Untreated (UT) wild-type, Puma-deficient $\left(\mathrm{Puma}^{-1-}\right)$, or Noxa-deficient (Noxa ${ }^{-1-}$ ) embryos had low levels of p53 immunoreactivity. $\boldsymbol{i}-\boldsymbol{I}$, Untreated embryos also exhibited low immunoreactivity for activated caspase-3.e, $\boldsymbol{g}, \boldsymbol{m}, \mathbf{0}$, Wild-type E13 embryos exposed to $25 \mathrm{mg} / \mathrm{kg}$ AraC for $6 \mathrm{~h}$ in utero (TX) exhibited detectable p53 immunoreactivity $(\boldsymbol{e}, \boldsymbol{g})$ and widespread immunoreactivity for activated caspase- $3(\boldsymbol{m}, \mathbf{0})$ in the ventricular zone. In comparison, AraC-treated Puma-deficient littermate embryos displayed increased p53 immunoreactivity $(\boldsymbol{f})$ and reduced caspase-3 activation $(\boldsymbol{n})$. In contrast, AraC-treated Noxadeficient embryos did not exhibit increased 533 immunoreactivity $(\boldsymbol{h})$ and had significant activation of caspase-3 $(\boldsymbol{p})$. All genotype comparisons were made between littermate embryos. Scale bar, $20 \mu \mathrm{m}$.

provides NPCs with the greatest level of protection against DNA damage.

Several in vitro studies have found that the role of Noxa and Puma in cell death signaling is remarkably cell-type and stimulus specific. Deficiency of either Puma or, to a lesser extent, Noxa, has been reported previously to provide protection against ETOinduced apoptosis of mouse embryonic fibroblasts (Villunger et al., 2003). In other cell types, however, only one of these proteins appears critical for apoptosis. For example, adenovirus-mediated overexpression of Puma, but not Noxa, induced apoptosis in primary cortical neurons (Cregan et al., 2004). In these cells, exposure to the environmental toxin arsenite induced both p53dependent and -independent expression of Noxa and Puma, but only loss of Puma inhibited apoptosis (Wong et al., 2005). Although loss of Puma did not significantly reduce STS-induced death in NPCs, loss of Puma did provide protection against STSinduced death of thymocytes (Villunger et al., 2003). Puma also appeared to be the dominant mediator of DNA damage-induced apoptosis in lymphoid cells (Villunger et al., 2003; Erlacher et al., 2005). Conversely, motor neurons predominantly induced Noxa but not Puma after axotomy, and deficiency of Noxa was shown to reduce the extent of axotomized motor neuron death (KiryuSeo et al., 2005). Thus, the contribution of Noxa and Puma requires empirical determination for each apoptotic stimulus and for each cell type.

Noxa and Puma have also been implicated in p53-indepen- dent apoptotic pathways. Several other transcription regulators, such as hypoxia inducible factor- $1 \alpha$ (HIF1 $\alpha)$, E2F transcription factor 1 (E2F1), and p73, have been shown to induce the expression of Noxa and Puma independently of p53 in the CNS (Hershko and Ginsberg, 2004; Kim et al., 2004; Melino et al., 2004; Flinterman et al., 2005). We detected a dramatic increase in the expression of Noxa and Puma in p53-deficient NPCs exposed to STS. We found previously that STS induced rapid apoptosis in NPCs that did not require p53-mediated transcription (Akhtar et al., 2006). We also found that STS-induced NPC death could be inhibited by loss of p53 (Akhtar et al., 2006). Together, these results suggest that STS induces two phases of apoptotic death in NPCs. The rapid first phase is p53 dependent and transcription independent. The delayed second phase is p53 independent, transcription dependent, and may involve induction of Noxa or Puma by a transcription factor other than $\mathrm{p} 53$, such as $\operatorname{HIF} 1 \alpha$, $\mathrm{E} 2 \mathrm{~F} 1$, or $\mathrm{p} 73$. This model is supported by a recent study that showed that, in response to $\gamma$-irradiation, p53 rapidly translocates to the mitochondria and promotes apoptosis by priming the cell for a second "wave" of transcription-dependent death (Erster et al., 2004). If a similar model is present in NPCs, a prosurvival effect of Noxa or Puma deficiency after STS would only be revealed in NPCs that have lost p53. To our knowledge, p53/Puma or p53/ Noxa double-deficient NPCs have not yet been generated. Generation of such cells will be essential to determine the role of Noxa and Puma in mediating the p53independent component of STS-induced NPC death.

Our findings identify Noxa and Puma as regulators of apoptotic cell death of NPCs after genotoxic injury. We find that expression of both Noxa and Puma increases rapidly after treatment with a range of DNA-damaging agents. This increase is dependent on the tumor suppressor p53. Moreover, we show that loss of Puma protects telencephalic ventricular zone NPCs from DNA damage-induced death in vivo. Deficiency of either Puma or Noxa also protected NPCs exposed to genotoxic stress in vitro and reduced both caspase activation and cell death after this stimulus. Together, our results further our understanding of BH3only protein-mediated regulation of telencephalic NPC death.

\section{References}

Akhtar RS, Roth KA (2006) Regulation of neural stem cell death. In: Neural development and stem cells (Rao MS, ed), pp 97-122. Totowa, NJ: Humana.

Akhtar RS, Ness JM, Roth KA (2004) Bcl-2 family regulation of neuronal development and neurodegeneration. Biochim Biophys Acta 1644:189-203.

Akhtar RS, Geng Y, Klocke BJ, Roth KA (2006) Neural precursor cells possess multiple p53-dependent apoptotic pathways. Cell Death Differ, in press.

Bounhar Y, Tounekti O, LeBlanc AC (2002) Monitoring caspases in neuronal cell death. In: Apoptosis techniques and protocols (LeBlanc AC, ed), pp 35-59. Totowa, NJ: Humana. 
Burger RM (1998) Cleavage of nucleic acids by bleomycin. Chem Rev 98:1153-1169.

Chen L, Willis SN, Wei A, Smith BJ, Fletcher JI, Hinds MG, Colman PM, Day CL, Adams JM, Huang DCS (2005) Differential targeting of prosurvival $\mathrm{Bcl}-2$ proteins by their $\mathrm{BH} 3$-only ligands allows complementary apoptotic function. Mol Cell 17:393-403.

Cory S, Huang DC, Adams JM (2003) The Bcl-2 family: roles in cell survival and oncogenesis. Oncogene 22:8590-8607.

Coultas L, Huang DC, Adams JM, Strasser A (2002) Pro-apoptotic BH3only Bcl-2 family members in vertebrate model organisms suitable for genetic experimentation. Cell Death Differ 9:1163-1166.

Cregan SP, Arbour NA, MacLaurin JG, Callaghan SM, Fortin A, Cheung ECC, Guberman DS, Park DS, Slack RS (2004) p53 activation domain 1 is essential for PUMA upregulation and p53-mediated neuronal cell death. J Neurosci 24:10003-10012.

D'Sa C, Klocke BJ, Cecconi F, Lindsten T, Thompson CB, Korsmeyer SJ, Flavell RA, Roth KA (2003) Caspase regulation of genotoxin-induced neural precursor cell death. J Neurosci Res 74:435-445.

D'Sa-Eipper C, Roth KA (2000) Caspase regulation of neuronal progenitor cell apoptosis. Dev Neurosci 22:116-124.

D'Sa-Eipper C, Leonard JR, Putcha G, Zheng TS, Flavell RA, Rakic P, Kuida K, Roth KA (2001) DNA damage-induced neural precursor cell apoptosis requires p53 and caspase 9 but neither Bax nor caspase 3. Development 128:137-146.

Erlacher M, Michalak EM, Kelly PN, Labi V, Niederegger H, Coultas L, Adams JM, Strasser A, Villunger A (2005) BH3-only proteins Puma and Bim are rate-limiting for gamma-radiation- and glucocorticoid-induced apoptosis of lymphoid cells in vivo. Blood 106:4131-4138.

Erster S, Mihara M, Kim RH, Petrenko O, Moll UM (2004) In vivo mitochondrial p53 translocation triggers a rapid first wave of cell death in response to DNA damage that can precede 533 target gene activation. Mol Cell Biol 24:6728-6741.

Fei P, Bernhard EJ, El Deiry WS (2002) Tissue-specific induction of p53 targets in vivo. Cancer Res 62:7316-7327.

Flinterman M, Guelen L, Ezzati-Nik S, Killick R, Melino G, Tominaga K, Mymryk JS, Gaken J, Tavassoli M (2005) E1A activates transcription of p73 and noxa to induce apoptosis. J Biol Chem 280:5945-5959.

Grant S (1998) AraC: cellular and molecular pharmacology. Adv Cancer Res $72: 197-233$

Han J, Flemington C, Houghton AB, Gu Z, Zambetti GP, Lutz RJ, Zhu L, Chittenden T (2001) Expression of bbc3, a pro-apoptotic BH3-only gene, is regulated by diverse cell death and survival signals. Proc Natl Acad Sci USA 98:11318-11323.

Hande KR (1998) Etoposide: four decades of development of a topoisomerase II inhibitor. Eur J Cancer 34:1514-1521.

Hershko T, Ginsberg D (2004) Up-regulation of Bcl-2 homology 3 (BH3)only proteins by E2F1 mediates apoptosis. J Biol Chem 279:8627-8634.

Huang DCS, Strasser A (2000) BH3-only proteins: essential initiators of apoptotic cell death. Cell 103:839-842.

Jeffers JR, Parganas E, Lee Y, Yang C, Wang J, Brennan J, MacLean KH, Han J, Chittenden T, Ihle JN, McKinnon PJ, Cleveland JL, Zambetti GP (2003) Puma is an essential mediator of p53-dependent and -independent apoptotic pathways. Cancer Cell 4:321-328.

Kim JY, Ahn HJ, Ryu JH, Suk K, Park JH (2004) BH3-only protein Noxa is a mediator of hypoxic cell death induced by hypoxia-inducible factor 1alpha. J Exp Med 199:113-124.

Kiryu-Seo S, Hirayama T, Kato R, Kiyama H (2005) Noxa is a critical mediator of p53-dependent motor neuron death after nerve injury in adult mouse. J Neurosci 25:1442-1447.

Lindsten T, Golden JA, Zong WX, Minarcik J, Harris MH, Thompson CB
(2003) The proapoptotic activities of Bax and Bak limit the size of the neural stem cell pool. J Neurosci 23:11112-11119.

Liu LF, Desai SD, Li TK, Mao Y, Sun M, Sim SP (2000) Mechanism of action of camptothecin. Ann NY Acad Sci 922:1-10.

Luo X, He Q, Huang Y, Sheikh MS (2005) Transcriptional upregulation of PUMA modulates endoplasmic reticulum calcium pool depletioninduced apoptosis via Bax activation. Cell Death Differ 12:1310-1318.

Maric D, Barker JL (2004) Neural stem cells redefined: a FACS perspective. Mol Neurobiol 30:49-76.

Maric D, Maric I, Chang YH, Barker JL (2003) Prospective cell sorting of embryonic rat neural stem cells and neuronal and glial progenitors reveals selective effects of basic fibroblast growth factor and epidermal growth factor on self-renewal and differentiation. J Neurosci 23:240-251.

Melino G, Bernassola F, Ranalli M, Yee K, Zong WX, Corazzari M, Knight RA, Green DR, Thompson C, Vousden KH (2004) p73 Induces apoptosis via PUMA transactivation and Bax mitochondrial translocation. J Biol Chem 279:8076-8083.

Nakano K, Vousden KH (2001) PUMA, a novel proapoptotic gene, is induced by p53. Mol Cell 7:683-694.

Oda E, Ohki R, Murasawa H, Nemoto J, Shibue T, Yamashita T, Tokino T, Taniguchi T, Tanaka N (2000) Noxa, a BH3-only member of the Bcl-2 family and candidate mediator of p53-induced apoptosis. Science 288:1053-1058

Qin JZ, Stennett L, Bacon P, Bodner B, Hendrix MJ, Seftor RE, Seftor EA, Margaryan NV, Pollock PM, Curtis A, Trent JM, Bennett F, Miele L, Nickoloff BJ (2004) p53-independent NOXA induction overcomes apoptotic resistance of malignant melanomas. Mol Cancer Ther 3:895-902.

Rao MS (1999) Multipotent and restricted precursors in the central nervous system. Anat Rec 257:137-148.

Reimertz C, Kogel D, Rami A, Chittenden T, Prehn JH (2003) Gene expression during ER stress-induced apoptosis in neurons: induction of the $\mathrm{BH} 3$-only protein Bbc3/PUMA and activation of the mitochondrial apoptosis pathway. J Cell Biol 162:587-597.

Roth KA, D'Sa C (2001) Apoptosis and brain development. Ment Retard Dev Disabil Res Rev 7:261-266.

Schuler M, Maurer U, Goldstein JC, Breitenbucher F, Hoffarth S, Waterhouse NJ, Green DR (2003) p53 triggers apoptosis in oncogene-expressing fibroblasts by the induction of Noxa and mitochondrial Bax translocation. Cell Death Differ 10:451-460.

Semont A, Nowak EB, Silva LC, Mathieu C, Mouthon MA, May E, Allemand I, Millet P, Boussin FD (2004) Involvement of p53 and Fas/CD95 in murine neural progenitor cell response to ionizing irradiation. Oncogene 23:8497-8508.

Shibue T, Takeda K, Oda E, Tanaka H, Murasawa H, Takaoka A, Morishita Y, Akira S, Taniguchi T, Tanaka N (2003) Integral role of Noxa in p53mediated apoptotic response. Genes Dev 17:2233-2238.

Temple S (2001) The development of neural stem cells. Nature 414:112-117.

Vescovi AL, Snyder EY (1999) Establishment and properties of neural stem cell clones: plasticity in vitro and in vivo. Brain Pathol 9:569-598.

Villunger A, Michalak EM, Coultas L, Mullauer F, Bock G, Ausserlechner MJ, Adams JM, Strasser A (2003) p53- and drug-induced apoptotic responses mediated by $\mathrm{BH} 3$-only proteins puma and noxa. Science 302:1036-1038.

Wong HK, Fricker M, Wyttenbach A, Villunger A, Michalak EM, Strasser A, Tolkovsky AM (2005) Mutually exclusive subsets of BH3-only proteins are activated by the p53 and c-Jun $\mathrm{N}$-terminal kinase/c-Jun signaling pathways during cortical neuron apoptosis induced by arsenite. Mol Cell Biol 25:8732-8747.

Yu J, Zhang L, Hwang PM, Kinzler KW, Vogelstein B (2001) PUMA induces the rapid apoptosis of colorectal cancer cells. Mol Cell 7:673-682. 